\title{
A Socio-Technical Perspective on the Digital Era: The Lowlands view
}

\author{
Mark Govers \\ Pierre van Amelsvoort
}

\begin{abstract}
Given growing global competition, organisations face the dual challenge of creating workplaces that are, on the one hand, more productive, agile, and innovative, and on the other hand, healthy places to work. At the same time, we are facing a digital revolution with profound consequences in work and daily life. Digital technologies have potential opportunities, but also constraints. To make the transformation successful joint optimise of social and technical systems is necessary. The sociotechnical systems design theory (STS-D) and practice have focused the last 70 years on this challenge. Over the years, different STS lenses have developed like participative design (North America and Australia), democratic dialogue (Scandinavia) and organisation design (the Netherlands and Belgium, the Lowlands). All have in common the aim of designing modern organisations that are humane, productive, agile and innovative. Also, digital technology has developed over the years: from digitisation to digitalisation, and lately into digital transformation affecting societies, organisations and humans. With this article we take the Lowlands STS$D$ theory as perspective and we discover how this theory, especially the design sequence, should be adjusted to apply successful digital technology. First, we zoom in on digital technologies and its opportunities. Second, we zoom in on the STS-D Lowlands design theory its principles and organisational design sequence. The original design sequence requires adjustment from a digital technology perspective. We propose a combined approach from a digital-technical and social perspective. We end with new routines for designing modern $21_{\text {st }}$ century organisations that facilitate organisational and digital experts to jointly optimise both perspectives in practice.
\end{abstract}

Keywords: socio-technical systems design, systems thinking, digital transformation, workplace innovation, design routines and sequence, quality of working life, bureaucratic and agile organisation. 


\section{Introduction}

Given growing global competition and the predicted shortages in the labour market, organisations, nowadays, face the dual challenge of creating workplaces that are, on the one hand, more productive, agile, and innovative, and on the other hand, healthy places to work. There seems to be a need for workplace renewal to transform traditionally siloed organisations into modern $21_{\text {st }}$ century organisations that meet these challenges. In manufacturing, the term Industry 4.0 is widely used to frame this (Kagermann, Lukas and Wahlster 2011; Liao 2017; Stock and Seliger 2016). Laloux (2014) talks in more general term about reinvented organisations. In these 21 ste century organisations the human factor continues and remains to play a crucial role. Nevertheless, it calls for renewal of the workplace, with a focus on change structurally (through division of labour) and culturally (in terms of empowerment of staff) to enable employees to participate in organisational change and renewal and, hence, improve the quality of working life and organisational performance. Sociotechnical systems design (STS-D) theory is based on agile instead of siloed ways of organising, and, therefore, STS-D could help to transform these traditional, inflexible, and, consequently, organisations with limited innovative capability. Traditional siloed organisations, however, are defined by and embedded in their structures, support systems, decision making systems, facilities and IT systems. These organisations are, due to their focus on maximising the division of labour and central control of work processes, designed for stable environments and mass production. Hence, they are not well-suited to respond to the need to be agile in a dynamic environment with ever changing customer demands. Therefore, to realise new ways of organising an integral approach to systemic change in the organisation is needed.

Digital technologies, on the other hand, are in the spotlight and are unfolding at a fast pace. They offer new, unprecedented digital and technological opportunities to market new business models and related products and services. In order to fully utilise these opportunities, organisations should be able to cope with these technical features by jointly optimising technical with social features in their context (Walker, 2018). This implies that, besides the technical, improving quality of working life should be considered as well. STS-D theory has a long and standing tradition in jointly optimising both social and technical factors resulting in more and lasting effective organisations. Combining the digital opportunities and STS-D seems to be a promising combination.

STS originates from the insights from the Tavistock Institute in the 50s and 60s (Trist and Bamforth 1951; Emery and Trist,1969). In the study of the implementation of new technology in the Durham mines, two important lessons can be learned. First, only focussing on technology effected in a lower productivity and a decline of the quality of working life. Second, a participative approach with a simultaneous focus on technology and social aspects gave an improvement of both productivity and quality of working life. Nowadays in the digital area, we are confronted with the same question. How can the digital transformation with a dual focus be successful in terms of increased both productivity and quality of working life? With the lessons of the Durham case in mind, we think the STS-D approach has a good proposition.

Over the years, it has world-wide developed into various STS-D directions, like participative design in the USA, Canada and Australia, democratic dialogue in Scandinavia and organisation design in the Lowlands. (Van Eijnatten 1993; Mohr and Van Amelsvoort 2016). All have in common the design of modern organisations, that are humane, productive, agile and innovative (Mohr and Van Amelsvoort 2016). In this article we take the Lowlands STS-D view in which the division of labour is central (De Sitter et al 1997; Vriens and Achterbergh 2011). We consider division of labour to be key as it offers a common starting point for both digital and organisational design. The division of a transformation process into tasks and roles, which are allocated to people and machines leads to designing execution tasks (production structure) and related regulation tasks (control structure).

In the introduction article of this series, Claussen, Haga and Ravn (2019) wonder whether current STS theory still is a platform to deal with the challenges of globalization, digitalization and technological platforms or whether a new STS, which they call STS beyond, is needed. In this article, we approach STS beyond from the Lowlands view 
on STS by focusing on the following research question: what are the implications of digital technologies for Lowlands' STS-D theory, especially its design sequence? This is a relevant question for the following reasons. The transforming nature of digital technologies on economic systems, organisations and humans (McAfee and Brynjolfsson 2017, Brynjolfsson and McAfee 2014) has "blurring" effects on system and work relations. The system boundary between what is in-side and out-side becomes more fluid. The differentiation between executive and regulations tasks performed by man and machine also becomes more fluid. Consequently, these blurring effects would affect the design sequence of the Lowlands view on STS. The design sequence may have to incorporate digital affordances for designing 'joint optimisations' between digital technologies and people working in collaboration.

To understand the Lowlands STS approach for designing organisations in the digital era, we explain first in-depth its core organisational design principles. This is followed with a 'STS beyond' view on the Lowlands view by emphasising an integral design sequence to utilise the potential of digital technologies and improve quality of working life. We start the article with explaining our understanding of digital technologies and transformation.

\section{Digital technology and transformation}

Technological developments, like data analytics, robotics, big data, artificial intelligence and internet of-things, are positively and negatively affecting existing social relations in a political, cultural and economic sense (Bounfour 2016, Hann 2016). Minorities make their voices heard through social media, and by doing so influence public opinion. Children become addicted to their smartphones and alienated from physical reality. Mothers set up web shops and compete with large companies. It is, therefore, not a matter of digital technology per se but of the social impact of applying and using digital technology. These changes have consciously to be designed, in order for their effects to be or to become positive. In this contribution we zoom in on this and limit ourselves to the consequences in and for organisations. We show how this can be dealt with from an agile, socio-technical perspective.

Digital transformation integrates digital technologies into all aspects of society (Hanna 2016, Harari 2018). As a result, relationships and interactions between actors change fundamentally. Despite the fact that digital transformation is referred to as the fourth industrial revolution, this revolution goes through roughly three digital evolutionary phases (see figure 1):

- Digitisation is the first phase. It concerns the conversion of analogue carriers of data (paper) to digital carriers (databases). This phase began in the 1960s and is still in full swing.

- Digitalisation is the second phase. It concerns the adaptation of digital technology in business processes. The massive introduction of transaction and management information systems, such as enterprise systems (ERP), at the end of the 1980s marks this phase. This phase is still in full swing.

- Transformation is the third stage. It concerns the creation of new business models based on the possibilities of digital technology and platforms to integrate business processes. This third phase fundamentally changes the way in which organisations operate and how organisations realise value for customers. It also implies that the way they think about organising and managing has to transform and that they must learn to look more holistically. 


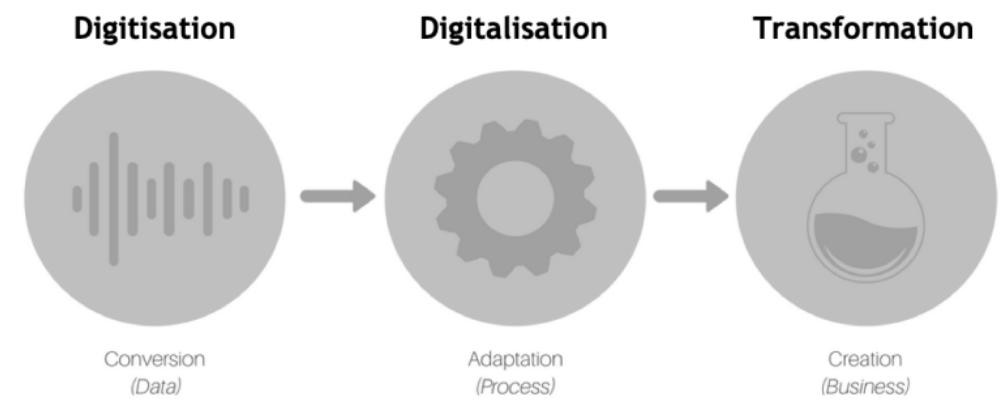

Figure 1. Phases of Digital Transformation (based on: Maltaverne 2017)

The digital transformation is unfolding at a fast pace. This offers new, unprecedented opportunities to market new business models and related products and services (e.g. Rogers 2016, Evans 2017). A business model describes the design of the creation, delivery and capture of value (Osterwalder and Pigneur 2010, Teece 2010; 2018).

New business models triggered by digital technology are, for instance, grounding on free, platforms, data, artificial intelligence (AI) and crowdsourcing. These grounds are, in practice, combined into actual business models. The free business model is possible once offerings to the market are converted into a digital service. The offerings can be copied without any additional costs and without loss of quality. It becomes free, prefect and instant (McAfee and Brynjolfsson 2017). WhatsApp and Skype are examples. The economic value of free comes from the network effects of bringing many users together and from the data users generate (e.g., preferences), which can be turned into revenues (e.g., via personalized advertisements). Viability can also be built on subscriptions. Free is, then, a stripped-down of the full fee version that has to generate revenues. Free business models often go hand-in-hand with platform driven business models (McAfee and Brynjolfsson 2017). Digital platforms bring supply and demand in an unlimited and unrestricted way together, which can result in networks with users running in the millions. Platforms often do not own the physical resources for actually delivering products or services. They just own the platform that facilitates interactions between demand and supply. Examples are Airbnb and Uber whom do not own hotels or taxis but make hotel stays and taxi rides possible. Data and AI go hand-in-hand as well. Interactions in business processes generate data related to behaviours of for instance customers suppliers and employees (MayerSchönberger and Ramge 2018). Analysing data reveals new intelligence to manage organisations and to feed decision-making processes. Based on gathered data and with AI, machines can take over defined decisions, like granting of loans. This trend is called data-driven decision-making (Brynjolfsson and McElheran 2016, Lepri et al. 2017). New business models can also emerge from involving the crowd, so-called crowdsourcing (McAfee and Brynjolfsson 2017, Hossain and Kauranen 2015). The idea is that the crowd has more wisdom then any organisation can ever hire. An interesting case is Hyperloop HTT in which they involve 800 engineers to develop a hyperloop transportation system without being employed and paid by HTT (Majchrzak et al. 2018).

Digital triggered business models often transform and disrupt existing industries; see the text box for two examples from healthcare. According to the European Commission (2018:1): "digital transformation holds the key to unlocking future growth in Europe". Threats are, also, lurking because it can overthrow existing business models and related products and services: so-called disruptive effects of digital technology (Mayer-Schönberger and Ramge 2018). Inspired by Sombert (1863-1941), the economist Schumpeter (1883-1950) talked in the 1930s about the process of creative destruction: successful applications of new technology, for example, destroy old professions and 
at the same time create new ones. To use the possibilities of digital technologies there is a need to rethink and design new ways of organising the work system.

Examples of unexpected, disruptive effects of digital technologies in healthcare (Philadelphia, 2019)

\section{Social robots}

A robot with speech recognition and machine learning was used in a care institution for mentally disabled people. The care givers disliked it, because they believed that face-to-face interaction is the cornerstone of good care. Yet the client told the robot much more than ever before to nurses. Besides the ethical question whether this information can be used in the treatment, it implies that the work of nurses will change. Care givers should be able to analyze the interactions between the mentally disabled person and the robot in order to better understand the needs and peace of mind of mentally disabled person. This requires more complex competences from care givers. In other words: the robot changes the nature of the nurses' work by requesting different and more complex competences.

\section{Smart incontinence}

Diapers contain wearables to measure moisture, so that it is known when the diaper needs to be replaced in contrast to planned moments. This was at odds with the planning of the carer givers. Due to the sensor changing the diaper depended on the individual patient and his/her context. Analyzing the data showed for instance, that after regular replacement of a diaper the moisture meter of some patients went over the trace-hold again after they were set straight. From this notion, patterns were discovered that each patient has his/her own pattern of needing to urinate and is reacting differently to the way the diaper was changed. So, in other words digital

\section{STS-D theory: The Lowlands view}

Digital transformation impacts the division of labour and the division between man and machine. Digital technologies fade away the boundaries between organisations (for example: virtual teams) and make it blurry. Customers are more and more involved in the core work processes (for example: booking an airplane ticket), horizontal co-ordination on digital platforms is possible and execution and control can be integrated (for example: Amazon). Machines are replacing humans in routine and non-routine work and new types work for humans are emerging. For this division of labour between man and machine, it is important to have a common understanding about 'what is work?'. In this respect, the Lowlands STS-D theory provides a general and valuable framework, given that core work processes are rooted in a dynamic systems-theoretical perspective of work and organisation (Kuipers, Van Amelsvoort and Kramer 2018, De Sitter 1994, De Sitter et. al. 1997)

An organisation's core work process is the primary process of an organisation, such as, making products or providing services (Van Amelsvoort and Van Hootegem 2017). How these products or services are produced, i.e. how the core work processes are organised, largely determines the extent to which the organisation's products or services create added value for customers. Hence, orchestrating an organisation's shift towards workplace renewal: related goals, performance and quality of work, typically requires a redesign of the core work process. In this respect, STS-D theory provides a valuable framework, given that core work processes are rooted in a dynamic systems-theoretical perspective of work and organisation (Kuipers, Van Amelsvoort and Kramer 2018; De Sitter 1994, De Sitter et. al. 1997). The design of the core work processes determines the needed degree of (central) coordination and the possibilities for (shop floor) self-organising capabilities. A maximum division of labour creates the need for central co-ordination and hierarchical control whereas a minimum possible division of labour creates conditions for self-organisation and horizontal co-ordination (i.e., more job autonomy). Given that organisations are complex social systems, a systemic view as offered by STS-D is helpful in redesigning organisations when 


\section{E UROPEAN JOURNAL OF W ORKPLACE INNOVATION}

required by changing economic circumstances or introducing digital technologies. Organisations based on maximum division of labour have difficulties in coping with economic changes and the digital transformation, while agile, flow-based organisations are better equipped to handle change and turbulence (Kuipers et al. 2010).

The Lowlands STS-D theory suggests that, as a result of the division of labour, the organisation is an interacting network of people and machines executing tasks and roles, using (ICT) technological instrumentation, tools and machines. These tasks and roles are thus allocated to individuals, teams, departments, business units and to a network of organisations. STS-D makes the distinction between production and management in the following manner:

1. the structure of executing activities (the production structure of the core work processes: PS) and

2. the structure of control activities to manage the core work processes (the control structure: CS).

In both execution and control, digital technology will take over work of humans. At the same time, new work will occur. In STS-D a role or task is the work that needs to be done, which is often related to the work of other people/machines. This is not limited to people in one organisation. All these roles and tasks together constitute the whole of the core work process. In other words, all these roles and tasks together complete the whole task of, for example, a team or an organisation. The notion of whole tasks implies, in theory, that there is no division of labour at all, such as for example, when a team is making a complete end-product from start to finish. This is, however, almost never the case, and therefore, roles can be seen as nodes interacting with other interdependent nodes to complete the core work process (see figure 2). A node is a point where several inputs and outputs from different interaction partners come together to do the work.

In STS-D, as an offspring of systems theory, inputs are transformed into outputs as in the input-throughput-output model. The core work processes function in a similar vein at every level, such as at the level of tasks, jobs, teams, departments and the organisation as a whole. At the nodes, inputs are therefore transformed into outputs or outcomes, meaning that resources are transformed into products or services. Interaction between nodes, for example, the collaboration of individuals in a team, is necessary for a number of reasons, such as: the exchange of information, knowledge creation, planning and/or coordination, and deliberation. Team members are, for example, dependent on each other's task execution. At the nodes, interactions happen with both internal and external interaction partners. In order to ensure productivity either directly or indirectly, these various interactions between nodes need to be established at the right time, between the right jobs, with the right material or information and at the right place. Otherwise, production gets delayed or mistakes become a risk. 


\section{E UROPEAN JOURNAL OF W ORK P L A C E IN N O VA TION}

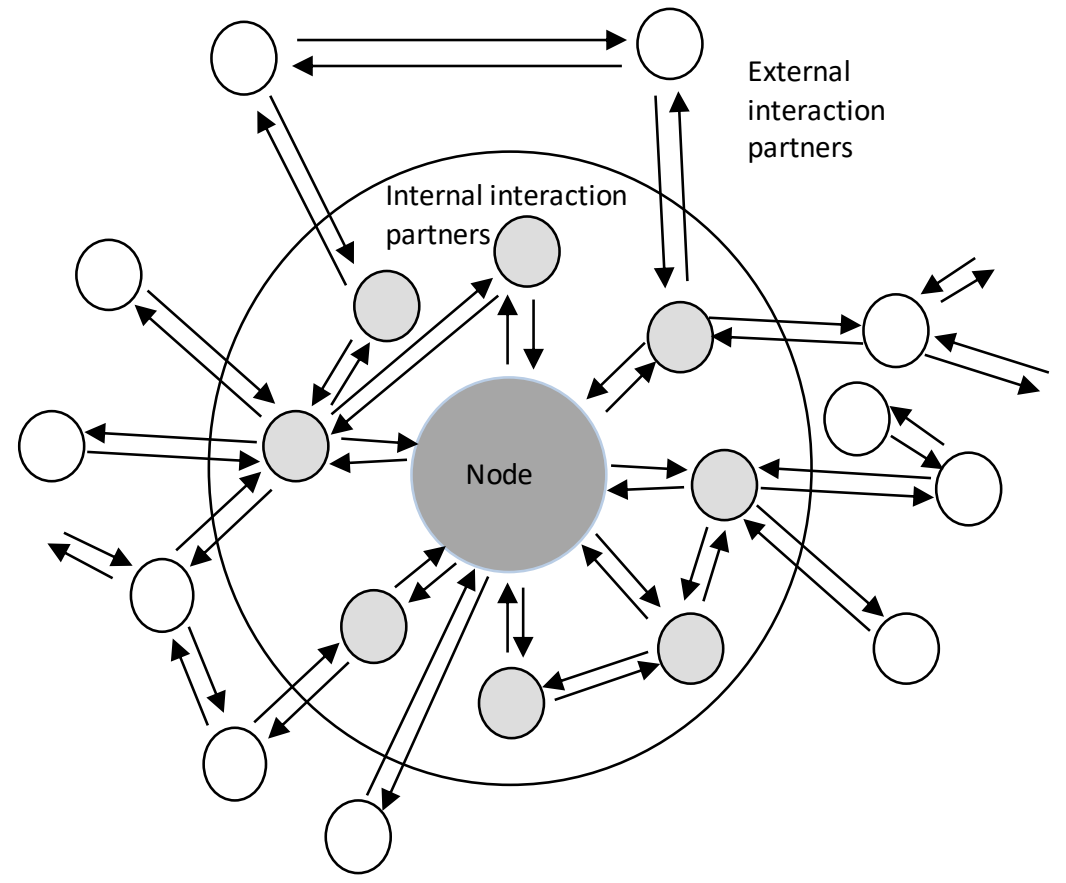

Figure 2. The interaction network with nodes (Kuipers et al., 2010)

However, these (un)planned interactions or deliberations (Pava 1983) between nodes can suffer from interferences, due to variance that is not accounted for in the original planning of the production in the core work processes. For instance, in the building and construction industry, different parties have to collaborate to get the job done, as they are connected in specific supply-chain models. If one of the parties withholds information or drops out of the project unexpectedly, this will interfere with the other parties' capability to get the job done. In this sense, a node has to cope with two types of variance (Vriens and Achterbergh 2011):

- external variance: such as lack of information, communication errors, changing customer demands, incomplete input, conflicting, ambiguous or competing demands;

- internal variance: human errors, technical disturbance, invalid and inflexible capabilities, shortage of resources.

The key question that arises is how can organisations deal with these types of variance at the nodes in ways that do not disrupt the production process? According to Lowlands STS-D, to deal with such variance, organisations should on the one hand, redesign the division of labour in such a way that the complexity of the interaction network can be reduced, and on the other hand, increase job control possibilities so that variances can be controlled at the source. In this respect, De Sitter suggested to create simple organisations but make jobs complex, meaning that jobs become rich and varied (De Sitter et al. 1997). In other words, bureaucracies create jobs that are too simple for the complex changes in the environment. STS-D create complex jobs so that organisations can deal with that complexity in flexible ways (Mohr and van Amelsvoort 2016).

\section{The relation between the division of labour and productivity}

The productivity of an organisation is related to its capability to cope with strict external demands: namely, business and customer demands for variety (product mix), and uncertainty about both short- and long-term planning. Therefore, the capability to meet these external demands is contingent upon the needed internal variety: namely 
meeting requirements in relation to efficiency, quality, flexibility, and innovation. Only if organisations can internally vary how they operate, are they able to meet the external requisite variety (Ashby 1969):

1. Organisations that are based on the principle of maximum division of labour, which, in turn, leads to complexity and rigidity (Achterbergh and Vriens 2009) (see figure 3). This maximum division of labour can be counterproductive for a number of reasons: simple jobs, i.e., the formation of silos between functional departments, each pursuing fragmented goals and interests;

2. Complex interactions, i.e., long hierarchical communication lines, central decision-making, and a large number of rules and meetings.

These organisations have many nodes and are, therefore, exposed to the risk of many interferences in the core work processes when the work cannot be performed as initially planned. Figure 3 indicates that the performance of the core work processes requires several dependencies in terms of control (c) and execution.

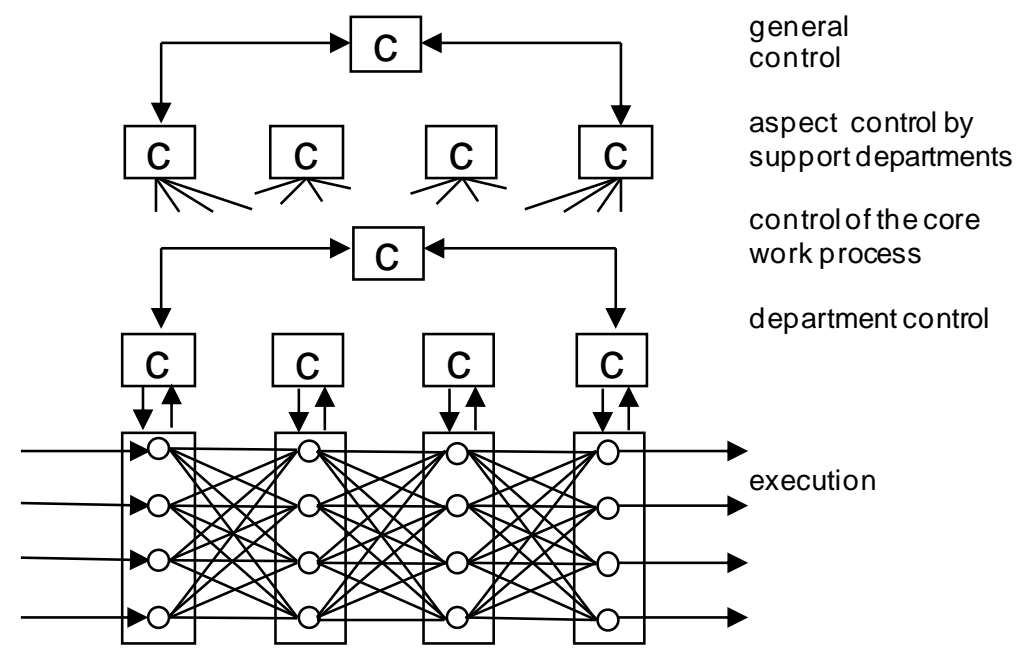

Figure 3. The principle of maximum division of labour (Kuipers et al. 2010)

STS-D aims to reduce complexity by minimising the division of labour (see the section on Lowlands' STS-D principles and design sequence below) and to create the structural conditions for (multi)organisational agility. On one hand digital technologies makes the reducing of the division of labour possible, on the other hand organisations based on minimum division of labour can use more fruitful the opportunities of digital technology.

The relation between the division of labour and employee involvement

The division of labour does not only affect productivity but also the quality of working life. For instance, Karasek's Job Demand-Control model (Karasek 1979, Karasek and Theorell 1990) (see figure 4) suggests that work organisation, specifically, high control (autonomy) in performing tasks is crucial in transforming job demands from risks and stress drivers into learning opportunities. 


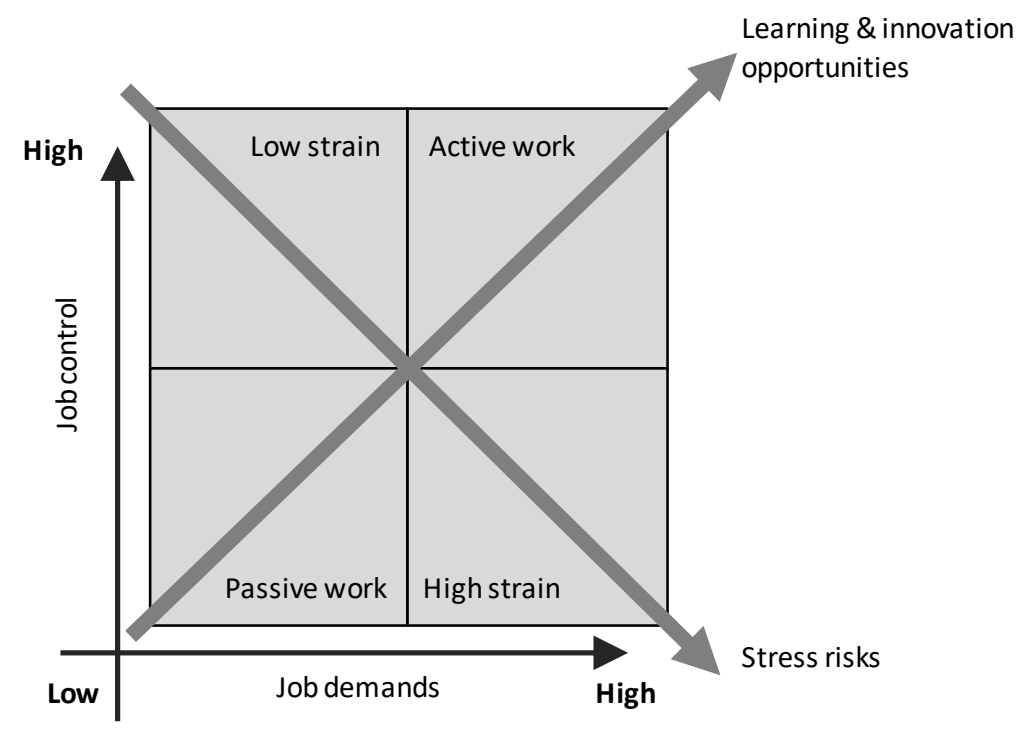

Figure 4. The Job Demand Job Control model of Karasek (1979, 1990)

In this model, job demands are seen as stressors such as work overload, unpredictable demands, time pressure, role ambiguity, interference, and emotional and physical demands. Job control is the combination of autonomy, decision latitude, instrumental support from colleagues, constructive performance feedback, craftsmanship, flexible resources, leaders' appreciation and support, accurate information, and communication. In this respect, there is evidence that high job demand and low job control are important predictors of psychological stress and illness. In addition, De Sitter (1994) claims that job control leads to involvement and motivation, which translates into positive effects on indicators such as absenteeism, turnover and stress. Moreover, there is evidence that a combination of high job demand and high job control in the form of active work is a predictor of an innovative organisation (De Sitter 1994).

In sum, job control is an important predictor for employee involvement and, as such, an important issue to keep in mind while introducing digital technologies. Indeed, STS-D proposes that, by increasing job control, employees are stimulated to learn, better equipped to deal with interference and, thereby, better prepared to respond to challenges arising from job demands. This increased level of job control does not only affect employee involvement but also serves the organisation by affording the possibility to better mobilise the use and development of human talent (De Sitter 1994), and thereby enable the goals of an agile organisation. By applying digital technology, human job control possibilities for all actors should be kept in mind.

\section{Lowlands' STS-D principles and design sequence}

Now that we have explained the general theory of STS-D, we address its strategic relevance first. In the next section, we discuss how these strategic choices can result in an operationally robust design. Robust means that interferences in the core work process are minimised and, if they occur, can be effectively dealt with. According to the opensystem principle, the design of organisations needs to be strategic, and should include all stakeholder perspectives. This is in stark contrast to the focus on shareholder value alone often witnessed in traditional organisations (Achterbergh and Vriens 2009). From an STS-D perspective, in line with the open-system principle, diagnosing, designing and changing organisations needs to be done by considering environmental conditions and strategic 
business choices. These strategic choices, in turn, impose requirements on the organisation, the "burning platform", and dictate the desired direction (see also Adler and Docherty 1998). Moreover, it is highly recommended that the design is drafted in co-creation with the different stakeholders. Indeed, the best guarantee for success is to fetch the whole system into the room (Weisbord 2004). This points to the importance of employee involvement, a hallmark of workplace renewal. In the traditional Lowlands STS-D theory, strategy is the starting point and sets the requirements for the design and the design process. From a digital perspective, strategy still remains the starting point. However, as digital technologies offer new types business models - like free, platforms, data and AI - which are continuously developing, strategic decision making becomes an integral part of a continuous (re-)design process.

Apart from strategic choices, we need robust organisations which can cope with the demands of flexibility and innovation in a dynamic world. Hence, from the STS-D perspective, robust organisation design is based on the following three principles on which the design sequence grounds (Van Amelsvoort 2000). First principle is to reduce complexity in the division of labour in the core work processes (PS) by focusing on customer order families. Reducing complexity can be achieved by the introduction of parallel processing (i.e., factory in a factory or between factories or a network in a network). Parallel processes (a) afford a better business focus, (b) create the conditions for decentralised control and horizontal co-ordination (see also principle 2), and (c) custom made technology can be applied. Parallelisation is defined as creating parallel streams of orders based on different customer families (e.g., markets, type of product). According to this principle, the design of the core work processes is based on the type of customers and their orders. This implies identifying customer families (orders) that show homogeneity in terms of business demands, and, therefore, impose identical constraints on the manner in which the production process must be carried out. Identifying these customer families involves finding criteria to divide customers into relatively homogeneous subsets with different strategic demands. For example, a construction company builds tangible products. However, renovating a house or building a hospital represents completely different core work processes with different strategic demands. Hence, a miniature organisation can be formed around these subsets of customer orders (i.e., one for house renovations and another one for commercial buildings) that each complete the process from a to $\mathrm{z}$ for this group of customer orders. The application of digital technology can also be customer focussed. In other words, the whole task is performed by a relatively self-organising group (i.e., autonomous work teams). We refer to the process as parallelisation (figure 4). In other words, parallel order streams are created, with each being maximally interdependent within the stream, but minimally dependent across streams. This implies the design of whole tasks and the creation of self-organising (virtual) teams, units and communities of work which are smaller in scale. Segmentation of the core work processes can help to reduce process complexity and create teams of 8-10 people. Segmentation is defined as cutting the flows of orders into parts, in such a way that a whole task of activities with high interdependency is created (i.e., De Sitter's complex jobs at team level).

The second principle is to increase the local (job and team) control capability and horizontal coordination by decentralisation: self-organisation and a healthy control structure. In an effective hierarchy designed to deal with turbulence, the different levels of control (i.e. layers of the organisation) have added value in terms of operational and strategic control. That is, flexible and innovative organisations are structured in such a way that they can react fast both at an operational and at a strategic level. To achieve operational control, work teams are self-organised at the operational level. Operational control is the combination of internal control (job autonomy, i.e., decision-making authority, technological variation possibilities, flexible access to means) and external control (co-ordination, team members' support, recognition, feedback, and influence). According to Ashby's law of requisite variety, control capability at a node (in this case, the self-organised team) is necessary in order to resolve interference at the place where it occurs and to prevent or reduce quality problems, delivery time deviations, or productivity losses (Ashby 1969). To achieve strategic control, different (business) units are set in place. Strategic control is necessary to reduce frequent interference among self-organising units and to explore innovations. Moreover, in dynamic situations, both operational and strategic control imply learning. The preconditions for control and learning are: Participation in goal setting and purpose definition, as well as effective feedback mechanisms for inspiration and learning, as in the 
Job demand Job control-model (but now on the level of a team for example). With human job control in mind, digital technologies can help to increase horizonal co-ordination.

The third principle is to congruent infrastructure (technology and facilities) and HR systems: minimum critical specification (Cherns 1987). Because the units in the organisation have different business demands, they will also have different support demands. A supporting HR system, for example, should differ between teams of technically skilled employees operating on the shop floor and administrative teams skilled in financial issues working in the office. Therefore, the design of the different support systems and technology should follow the first two principles mentioned above. Moreover, their design should be based on diversity instead of 'one size fits all' and should be focused on providing support instead of controlling.

To design agile organisations, De Sitter $(1986,1994)$ original developed a three-step design sequence based on the aforementioned principles. As said, after the strategic decision making, a distinction is made in first the production structure, second the control structure, and third the technical systems. It is only a distinction; in practice the design process has a non-linear character. This sequence is based on the well-known slogan 'first organise, then automate'. However, due to the insight that digital technologies create new opportunities for new business models, and therefore new processes, tasks and roles, the original sequence should be adjusted. We suggest adjusting the strategic decision-making process. Digital technologies make it necessary to simultaneously discover digital opportunities and constrains with the design of the production structure (step 1) and also the same with the design of the control structure (step 2). The adjusted three-step, non-linear sequence boils down to the following.

The first step is about the design of the production structure, or how an organisation produces its products or services. If we assume that strategic positioning, such as the need for flexibility, innovation and healthy work, has been carried out as a starting point, one needs to first design the core work process. The design starts with sorting customers into customer families or product families which have different demands. For each family the different processes should be mapped. With these process maps now the opportunities of digital technology can be researched: which tasks in the process can be replaced by (digital) technology, which new tasks occur, which tasks are done by humans (workers or customers). So now the (new) processes can be organised. It is also possible that new products or services, or new customer families may emerge from the opportunities of digital technology. Consequently, strategic choices can be discussed again. In any case, this design of the production structure is done by focusing on the overall picture and then on the details (i.e., first on the whole, then on the parts). Based on the different customer families with different demands (see principle 1), this means that one starts with creating the different (business) units, then the different departments within these units, and finally, ends with the design of the work teams and jobs. In combining the design of the production structure with scouting for digital possibilities, the requirements for the design of digital technology is brought more profoundly and design-theoretically to step 1. This also counts for step 2 the design the control structure.

The second step is the design of the control structure, or how the core work process and supporting processes are managed. It comes down to a redistribution of control capabilities through the design of the management structure. This control structure is designed in reverse order, in other words, from the parts to the whole (i.e., bottom-up and not top-down). That is, first one determines what can be controlled at the (lowest organisational) local level (i.e., team and job level), subsequently what can be organised at the level of a larger organisational operating unit (above that level), and finally what needs to be controlled at the (highest) organisational level. Next, the consultation and decision-making structure can be further elaborated in detail. The principle here is that emerging problems require autonomy to solve them at the level where those problems occur. This implies that the task of managing the core work processes should as much as possible migrate to the lowest organisational level. Also, in this step opportunities for applying digital technologies are researched. For example, digital technologies introduce the possibility that some aspects of control may be automated or better informed, which in turn, may eliminate or provide new 'assistance' to prior control tasks allocated to humans, or may enable or require new control tasks that 'augment' 
human roles. Digital technology makes also the distinction between execution and control blurry; more on this in the discussion section. The design theoretical consequence is that the first two steps - the design of the production and control structures - should be designed with digital in mind. During these steps, the (new) opportunities and possibilities of digital technologies should already be taken into account. Until now in Lowlands' STS-D, the design and deployment of information technology was a derivate of the design decisions made in steps 1 and 2. Effectively, we argue that digital technology becomes an integral part of designing work and organisation.

In Lowlands STS-D, information technology has always been seen as a derivative of step 1 and 2 (Govers and Südmeier 2016). This is no longer tenable, because digital technology is penetrating more and more deeply into work systems and organisations. Previously, work was done with digital technology, in which we now work more in digital technology. Digital technology has move beyond technology by becoming organisational.

The third step is the actual design of the technical systems (and other support systems), or how information streams support production and management. It focusses on the various (technical and support) systems which are required in the new organisational architecture. These systems include IT and support systems (HR, quality etc.). Here the rule is that these systems should support and not control the production and control structure.

It may sound as if the adjusted three design steps are mixed in a one large melting design pot. That is not the case. The sequence between the three steps remains feasible and valid, because it sets the order of the design focus. The sequence of and focus on (1) production structure, (2) control structure and (3) technical systems offer clarity for workers and designers participative designing workplaces, work systems and organisations. In step 1 and 2 the opportunities of digital technology are actively and profoundly scouted, and, consequently, digital requirements can be developed. In step 3, the 'final' infrastructure of digital technologies is actually designed. The realization of the technical infrastructure is seldom first time right; from a key STS design insight, it is known that designs by definition are incomplete and constantly in development. The socio-technical optimisation is a continuous process. This is especially apparent for digital technologies, because digital opportunities are constantly in development. The ability to continuously socio-technical optimise requires, therefore, new design routines in order for workers, digital experts and organisational experts to effectively collaborate for designing humane, productive and innovative organisations.

\section{New design routines}

As digital technology will co-determine work and organisation design, the languages and logics of both the digital and organisation worlds should be bridged, if not blended, when actually designing (Govers and Van Amelsvoort 2018).

First of all, we refer to customer experience. Customers become an essential part of the (core work) process. They carry out parts of that process themselves and find it self-evident and service oriented. Internet banking is an example. Since customers, for instance, enter their own payments themselves, the bank has fewer administrative tasks to perform. It is important that the customer does not experience this as a burden but as a plus. This is why banks are making their digital infrastructure more user-friendly and extending it to different platforms: mobile in addition to computers.

Secondly, we refer to operational agility. Work processes, especially with regard to services, are increasingly taking place within digital platforms. Processes are put together by bringing together basic 'Lego blocks', so that new business models can be put on the market quickly. Setting up different web shops for specific target groups, in which the same warehouses are used at the back (back office), is an example. 
Thirdly, we refer to workforce engagement. Employees may be given more decision-making powers. This is possible because digital technologies can offer more useful and accessible analyses of situations to employees in the work processes. An employee of a service desk can immediately see what type of customer is on the line, as the customer profile is immediately visible. The employee can better estimate what to do based on the customer's historical data and on the product's historical data. It empowers employees, which has a positive effect on work experience and involvement.

It sounds paradoxical: in order for digital technology to land effectively in organisations, technical design questions must be preceded by social design questions. For example:

- What new interaction possibilities does digital technology offer for a different collaboration between customerorganisation, employees and management staff?

- What does it imply for quality of the organisation (efficiency, quality, flexibility, innovation and sustainability)?

- What does it imply for quality of working life (challenging and active work for people)?

After the answers to these questions have been formulated strategically, technical design questions are on the agenda, for example:

- With which digital technology can the desired different collaboration in organisations and processes be efficiently realised?

- Which conditions are needed for this?

- What is the change/transformation plan?

In addition to the sequencing of design questions, we recommend abandoning five dominant bureaucratically driven design routines, and instead embracing five agile, socio-technically driven design routines. On the one hand, this is necessary because organisations are confronted with increasing variety and dynamics. This requires routines that encourage, rather than hinder, the speed of action. On the other hand, it is necessary to find and continue to find a maximum 'joint optimisation' between digital technology and people working in collaboration.

The five new to be learned routines are independent of digital technology. They are, however, decisive for effectively landing digital technology with a positive transformative effect on organisations and people. For organisations and professionals who stick to the current routines we predict an accelerated and painful end. The transition to and from the next five routines is crucial for the effects of digital technology to land positively in organisations and for people in organisations. Firstly, to let go functional thinking about organisations for processand chain-focused thinking. Based on the requirements and wishes of customers or customer families, processes are organised in organisational forms made up of relatively independent units that are able to respond quickly to customer demands and innovate quickly. The starting point for the design is the intended strategy of the organisation. The primary process and/or primary chains between organisations form the starting point for the design. Secondly, to let go of one-fits-all for one-fits-one designs. Today's digital technology offers plenty of options to design and implement various, customised solutions. This possibility is still being sought too little, because we still think and act too much from the experience of complex and expensive implementation and management costs experienced, for example, in the ERP era. Thirdly, to let go the expert, top-down and cascade design approach for a participatory, bottom-up and scrum design approach. The dynamics in the environment are so high that the classical approach no longer works: Too expensive and too time-consuming. Instead of elite clubs of (often technical) experts who design a complex IT system with associated working methods top-down, users will design, test and commission organisational and digital processes together with IT and organisation experts in short sprints. In essence, this becomes a continuous design process. Fourthly, to let go the 'do more of the same' approach for a 'do different' approach. In a continuous design process, which has already been mentioned, it is also important to break away from the best practice myth. These practices have their value above all for the past and present; they 
offer no inspiration for designing the processes and organisational forms of tomorrow. Creativity, out-of-the-box and design thinking are new competencies that are just as important as technical and business knowledge and insights. Fifthly, to let go the consolidation of the current structures, processes and working methods for an ambidextrous approach to perpetuating and exploring, such that the organisation is increasingly in the status of continuous redesign. On the one hand, it operates in a perpetuation mode of efficiently and effectively delivering the current services and products. The current processes and forms of organisation are organised and managed for this purpose. On the other hand, the organisation shall ensure that an exploration mode exists for the possible creation of new working methods, processes and organisational forms. The development of new services and products would otherwise be undermined by the current organisational and management principles. In short, organisations and professionals must learn to think and act simultaneously in a perpetuation mode (the exploitation of the present) and an exploration mode (the creation of the new).

\section{Discussion}

In the aforementioned sections, we assume that digital technology is more than just technology. It has developed into features and (new) opportunities for designing work systems and organisations. Accordingly, we argue that the Lowlands STS design theory has to grow with this development and incorporate this in its design sequence. We also highlight that digital technology makes the distinction between execution and control blurry. Furthermore, digital technology takes work over from humans and creates new forms of work for humans. In our opinion, digital technology changes the nature of work, which, consequently, has ramifications for the Lowlands theoretical view on the nature work itself.

A fundamental difference between mechanic and digital technologies is that digital is also affecting - what in Lowlands STS is called - executive and control tasks. AI, for instance, is more and more used to control processes, and is doing it better than humans (McAfee and Brynjolfsson 2017). Where the focus of technology in general used to be on routine - repetitive and simple - tasks, digital technology enters the field of non-routine - complex and professional - tasks in rapid pace too. From a theoretical perspective, we believe that the Lowlands model to distinct work needs reconsideration. The distinctions between execution-regulation and routine-non-routine is too rough. Without wanting to be complete, we think the following adaptation of the Lowlands work model may be feasible. To understand the relation between digital technologies and work, we suggest defining work differently. Work could be specified by two dimensions: complexity of work and the elements of work. Complexity could consist of repetitive, deductive and explorative. Elements consist could consist of execute, regulate and organise. Figure 5 shows and explains the resulting model on the nature of work. The specific types of complexity and elements are explained in the figure below. This is a first thought and requires further deliberations and (action) research. 


\section{E UROPEAN JOURNAL OF W ORK P L A C E IN N O V A T I ON}
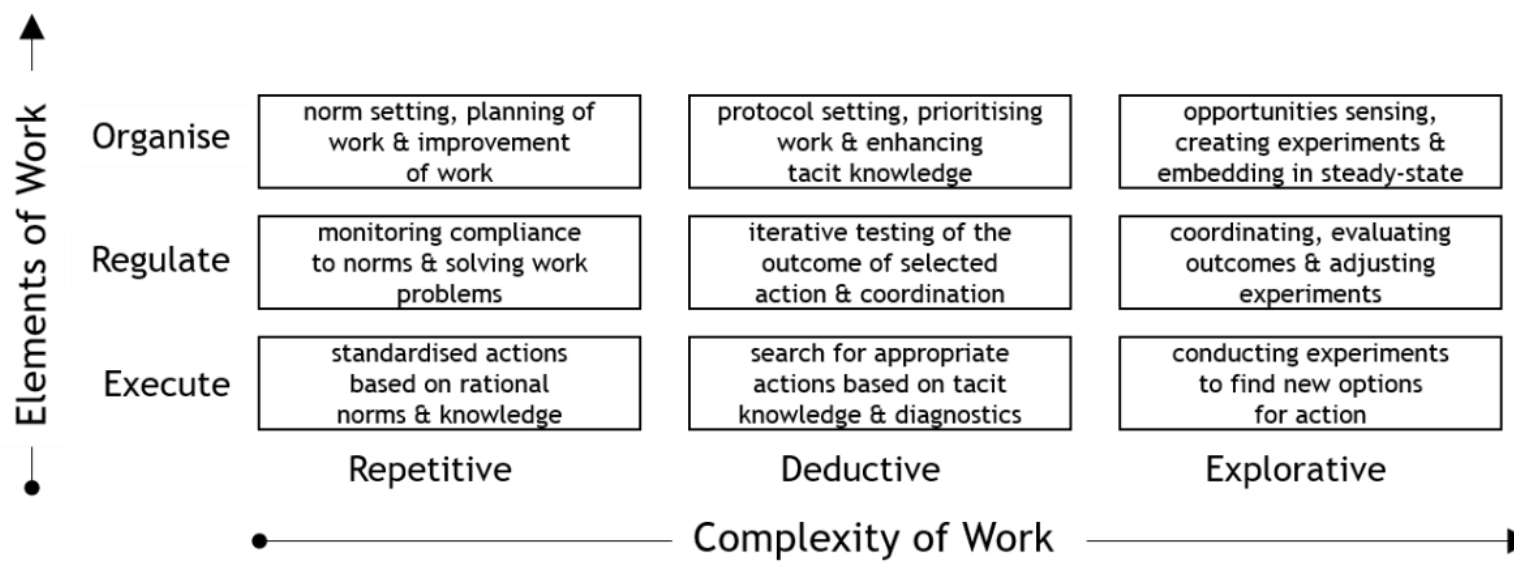

Explorative

Figure 5. The nature of work

In our opinion, especially intelligent digital technologies can develop potentials to 'penetrate' into all work elements of repetitive work and into regulate work elements of deductive and maybe even explorative work. From an STS perspective, we think that future work will have to be a combination of humans and machines working together. For this to be successful, we advocate that the participative design approach gains importance.

O'Neil (2016) demonstrates in her book 'Weapons of Math Destruction' the need for participative design. Too often, the algorithms behind big data, AI and machine learning ground on quicksand of weak correlations that are linked together into rational outcomes. This becomes an issue when these outcomes are being used as causal truths which are not questioned anymore by humans. Or worst, are used by humans as rational truths in decision-making processes. It becomes, according to O'Neil, even societal undermining when such algorithms are used in data-driven decision-making by machines.

The potential dangerous of AI shows that workers, digital experts and organization designers should participatively collaborate in a more integral manner. For effective participation, it is crucial that the collaborators understand each other's worlds and related languages and logics. Otherwise, Babylonian confusion of speech will occur with undesirable consequences for the joint optimisation and creation of humane, productive and innovative organisations. Digital experts, for instance, could be introduced to STS(-D) thinking to better understand the consequences of digital technologies for the functioning of organisations and for the quality of working-life for humans working with and in digital technology. On the other hand, STS designers, for instance, could show more interest in the functioning and mechanisms of digital technologies as well as its opportunities for designing organisations and workplaces. Understanding digital technology should, in our opinion, become an imperative for STS-D experts.

\section{Conclusion}

In this article we proposed a holistic design approach that integrates digital technologies into the STS design sequence. This design-theoretically implication for Lowlands' STS-D, thrives best if also new design routines are embraced that is necessary for a more successful participative design. Changing business demands and stakeholders bring in the demand for new ways of organising work systems. Current and future digital technologies can support this, even have unexpected, disruptive positive opportunities and/or negative effects. To utilise these positive opportunities and to minimise negative effects of digital technologies, the search to joint optimising of the technical 
and social system is crucial. With this article we have tried to lay a theoretical basis for this. Smart technology in smart factories also need a smart organisation 19. We invite both digital technology and organisation design communities to further develop this attempt pragmatically. Practical examples will help to deepen and enrich this theoretical approach empirically. This would help to successfully unlock the potential of digital transformation for the future growth in Europe from which all stakeholders related to modern 21st century organisations can benefit.

\section{References}

Achterbergh J., Vriens D. (2009). Organizations: social systems conducting experiments. Dordrecht: Springer.

Adler N., Docherty P. (1998). "Bringing business into sociotechnical theory and

Practice", Human Relations, 51(3) 319-345.

Amelsvoort P. van (2000). The design of work and organization. Vlijmen: ST-Groep.

Amelsvoort P. van, \& Van Hootegem G. (2017). "Towards a Total Workplace Innovation Concept Based Sociotechnical Systems Design”. In Workplace Innovation (pp. 281-299). Springer, Cham.

Ashby W. R. (1969). "Self-regulation and Requisite Variety”, in: Emery F.E. (Ed.), Systems Thinking (pp. 105121). London: Penguin Books.

Bounfour A. (2016). Digital futures, digital transformation. Springer.

Brynjolfsson, E., \& McElheran, K. (2016). The rapid adoption of data-driven decision-making. American Economic Review, 106(5), 133-39.

Brynjolfsson, E., \& McAfee, A. (2014). The second machine age: Work, progress, and prosperity in a time of brilliant technologies. WW Norton \& Company.

Cherns A. (1987). "The principles of sociotechnical design revisited”. Human Relations, 40( 3), 153-161.

Eijnatten F. van, (1993). The paradigm thatchanged the workplace. Assen/Stockholm: Van Gorcum/Arbetslivscentrum.

Emery, F. E., \& Trist E. L. (1969). "The causal texture of organizational environments". Sysems thinking, 1, 245262.

European Commision (2018). Investing in the future Digital Transformation 2021-2027. 8 June 2018. https://ec.europa.eu/digital-single-market/en/news/investing-future-digital-transformation-2021-2027

Evans, N. D. (2017). Mastering Digital Business: How Powerful Combinations of Disruptive Tehnologies are Enabling the Next Wave of Digital Transformation. BCS.

Govers, M., \& Südmeier, P. (2016). Applying enterprise information technology from a socio-technical perspective. In Co-creating humane and innovative organizations: Evolutions in the practice of socio-technical system design (pp. 289-302). Global STS-D Network.

Govers M.J.G. \& P. Van Amelsvoort P. (2018). Digitale technologie vereist andere ontwerproutines. AG Connect, August 2018 (no. 8).

19 network we are learning from each other and by sharing experiences, theories and tools. 
Hanna N. K. (Ed.). (2016). "Mastering digital transformation: Towards a smarter society, economy, city and nation". In Mastering Digital Transformation: Towards a Smarter Society, Economy, City and Nation (pp. i-xxvi). Emerald Group Publishing Limited.

Harari Y. N. (2018). 21 Lessons for the 21st Century. Random House.

Hossain, M., \& Kauranen, I. (2015). Crowdsourcing: a comprehensive literature review. Strategic Outsourcing: An International Journal, 8(1), 2-22.

Kagermann H., Lukas W., Wahlster W. (2011). Industrie 4.0 - Mit dem Internet der Dinge auf dem Weg zur 4. industriellen Revolution. In: VDI Nachrichten, Issue 13, (2011).

Karasek R. A. (1979). "Job demand, job decisions latitude and mental strain; implications for job design". Administrative Science Quarterly, 24 (2), 285-307.

Karasek R. A., \& Theorell T. (1990). Healthy work; stress, productivity and the reconstruction of working life. New York: Basic Books.

Kuipers H., \& Amelsvoort P. van, (1990). Slagvaardig organiseren, inleiding in de sociotechniek als integrale ontwerpleer. Deventer: Kluwer.

Kuipers H., Amelsvoort P. van, \& Kramer E.-H. (2018). Het nieuwe organiseren: alternatieven voor de bureaucratie. Leuven: Acco.

Laloux F. (2014). Reinventing organizations: A guide to creating organizations inspired by the next stage in human consciousness. Nelson Parker.

Lepri, B., Staiano, J., Sangokoya, D., Letouzé, E., \& Oliver, N. (2017). The tyranny of data? the bright and dark sides of data-driven decision-making for social good. In Transparent data mining for big and small data (pp. 324). Springer, Cham.

Liao Y., Deschamps F., Loures E. D. F. R., \& Ramos L. F. P. (2017). Past, present and future of Industry 4.0-a systematic literature review and research agenda proposal. International journal of production research, 55(12), 3609-3629.

Majchrzak, A., Griffith, T. L., Reetz, D. K., \& Alexy, O. (2018). Catalyst organizations as a new organization design for innovation: The case of hyperloop transportation technologies. Academy of Management Discoveries, 4(4), 472-496.

Maltaverne B. (2017). Digital transformation of Procurement: a good abuse of language? May 25, 2017. https://medium.com/procurement-tidbits/digital-transformation-of-procurement-a-good-language-abusebfcf565b957c Retrieved: on July 30, 2018.

Mayer-Schönberger V., \& Ramge T. (2018). Reinventing Capitalism in the Age of Big Data. Basic Books.

McAfee, A., \& Brynjolfsson, E. (2017). Machine, platform, crowd: Harnessing our digital future. WW Norton \& Company.

Mohr B. J. \&, Amelsvoort P. van (2016) (Eds.). Co-creating humane and innovative organizations: Evolutions in the practice Of Socio-Technical System Design. Portland, Maine (USA): Global STS-D Network Press.

O’Neil, C. (2016). Weapons of Math Destruction: How Big Data Produces Inequality and Threatens Democracy.

Osterwalder, A., \& Pigneur, Y. (2010). Business model generation: a handbook for visionaries, game changers, and challengers. John Wiley \& Sons

Pava, C. (1983).Managing new office technology: An organizational strategy. New York, NY: Free Press.

Philadelphia (2019). Philadelphia: giving your best. Downloaded on 23 Jan. 2019. 


\section{E UROPEAN JOURNAL OF W ORK P L A C E IN N O V A T I ON}

http://philadelphia.docufiller.nl/docupage/view/ZHBhZzoxNzQy/80cd29b9930508aa2950b910ea0d4402

Rogers D. L. (2016). The digital transformation playbook: Rethink your business for the digital age. Columbia University Press.

Sitter L.U., de. (1994). Synergetisch produceren, Human resources mobilisation in de productie: een inleiding in de structuurbouw. Assen: Van Gorcum.

Sitter L.U. de, Hertog J.F. den \& Dankbaar B. (1997). From complex organizations with simple jobs to simple organizations with complex jobs. Human Relations, 50(5), 497-534.

Stock T., \& Seliger G. (2016). Opportunities of sustainable manufacturing in industry 4.0. Procedia Cirp, 40, 536541.

Teece, D. J. (2018). Business models and dynamic capabilities. Long Range Planning, 51(1), 40-49.

Teece, D. J. (2010). Business models, business strategy and innovation. Long range planning, 43(2-3), 172-194.

Trist E. L., \& Bamforth K. W. (1951). "Some social and psychological consequences of the longwall method of coal-getting: An examination of the psychological situation and defences of a work group in relation to the social structure and technological content of the work system". Human relations, 4(1), 3-38.

Vriens D., \& Achterbergh J. (2011). "Cybernetically sound organizational structures I: de Sitter's design theory". Kybernetes, 40(3/4), 405-424.

Walker, M. (2018). Reassessing digital transformation. The culture and process change imperative. Harvard Business Review Analytic Services. (Supported by RedHat)

Weisbord M.R. (2004). Productive workplaces revisited: Dignity, meaning and communication in the $21_{\text {st }}$ century. London: Jossey-Bass/Wiley.

\section{About the authors:}

Dr. Mark Govers has been an associate professor in organisation and management at Maastricht University (CAPHRI School for Public Health and Primary Care, Maastricht University, Maastricht, the Netherlands). He holds a $\mathrm{PhD}$ on the intersection between business information technology and organisation development. Since 2016 he acts as a steward of both the North American and Lowlands Socio-Technical Systems (STS) communities respectively called the STS Roundtable and the Ulbo de Sitter Institute. Besides his academic work, he is a senior advisor at his own consultancy firm called Archypel Consulting.

Prof. Dr. Ir. Pierre van Amelsvoort is an expert in sociotechnical systems design and organisational change. He is a partner of the consulting firm ST-Groep. Between 1994-2007 he was professor by special appointment at the Nijmegen School of Management (Netherlands). Since 2010 he is guest professor at the Catholic University Leuven, K.U. Leuven (Belgium). Member of the global network of SmarT Organisation Design co-ordination team. 